\title{
The Design of a Drought Weather Index Insurance System for Summer Maize in Anhui Province, China*
}

\author{
Ying $\mathrm{Xu}^{1}$, Chao Gao ${ }^{2, \dagger}$, Xuewen $\mathrm{Li}^{3}$, Taiming Yang ${ }^{1}$, Xibo Sun ${ }^{4}$, Congcong $\mathrm{Wang}^{2}$, De $\mathrm{Li}^{5}$ \\ ${ }^{1}$ Agricultural Meteorological Center of Anhui Province, Hefei 230031, China \\ ${ }^{2}$ Department of Geography \& Spatial Information Techniques, Ningbo University, Ningbo 315211, China \\ ${ }^{3}$ College of Territorial Resources and Tourism, Anhui Normal University, Wuhu 241000, China \\ ${ }^{4}$ Guoyuan Agricultural Insurance Company, Hefei 230031, China \\ ${ }^{5}$ Meteorological \%XUDX of 6X]KRXIIQAnhui Province, Suzhou[234000, China
}

Received November 23, 2017

Accepted January 8, 2018

\begin{abstract}
We analyzed precipitation anomalies of summer maize in order to establish a drought weather index model that is based on tassel appearance and maturity stage as well as drought yield reduction rate. We utilized daily precipitation data encompassing the period between 1971 and 2010 from 15 agricultural meteorological observation stations within a summer maize planting area in Anhui Province, China. A compensation standard for insurance claims resulting from summer maize drought is proposed in this paper, and revisions are presented to the drought weather index by incorporating relative humidity from the initial insurance period. The results of this study enabled the generation of a summer maize drought weather index insurance product which was then tested within the city of Huaibei in Suixi County, Anhui Province. Results also demonstrate that application of a weather index insurance product can rapidly and objectively enable the provision of economic compensation in the aftermath of agricultural disasters.
\end{abstract}

Keywords: summer maize; drought; weather index; insurance

\section{Introduction}

Agriculture is a risky industry. Indeed, meteorological disasters are the main kind of natural catastrophes that endanger agricultural production and are closely linked to economic benefits (Zhang et al., 2011; Antón et al., 2013). Agricultural insurance is therefore an important mechanism that can help to reduce the cultivation risks faced by farmers, and can also mitigate perceived threats to agricultural production. Thus, if losses are suffered to crops covered by insurance, compensation will be paid to farmers (Coble et al., 2003; Thomas et al., 2007; Panda et al., 2013).

The concept of meteorological index insurance has been widely studied and applied in various countries over recent years. This kind of product is a new form of agricultural protection which determines both the insurance rate and loss compensation using objective meteorological data (Barnett et al., 2010; Bobojonov et al., 2014; Finger et al., 2014; Mornet et al., 2015). A number of steps have contributed to the development of meteorological index insurance, including an initial series of research studies that explored different crop

\footnotetext{
${ }^{*}$ Foundation item: Under the auspices of Research on threshold of meteorological factors of drought and waterlogging disasters in different spatial scale-A case study in the upper reaches of Huaihe river basin (41571018)".

† Corresponding author: E-mail: gaoqinchao1@163.com

Post address: Department of Geography \& Spatial Information Techniques, Ningbo University.
} 
types, including rice, maize, apples, and citrus (Leblois et al., 2013; Chen et al., 2017; Zhang et al., 2017). On this basis, a meteorological disaster claim index model was then designed to generate insurance contracts based on the relationship between reductions in crop yield and meteorological hazard factors (Jin et al., 2016). Judgements are therefore made about the level of disaster loss in order to carry out a division of risk and an assessment of meteorological index insurance that combines risk similarities and the variability of characteristics within a disaster environment (Liu et al., 2010; Cao et al., 2013). In terms of research methods, it is then important to select relevant meteorological indicators that are based on regional characteristics, including selecting approaches that incorporate the concepts of moving averages and polynomial fitting in order to accurately separate meteorological yields (Blanc et al., 2012). Probability functions, such as Beta and Gamma distributions, can then be applied to determine the risk probability of a given yield reduction rate at all levels and thus to determine the premium rate (Lu et al., 2008; Ozaki et al., 2009). In an international context, precipitation index insurance is commonly utilized in the USA, South Africa, and Mexico, for example, to mitigate the risks of drought and waterlogging disasters (Raphael et al., 2006; Barnett et al., 2010), while a meteorological index of citrus frost damage has been proposed for use in China as the compensation standard for this kind of issue. This index is based on risk analysis of annual minimum temperatures within the main production areas for this citrus fruit in Zhejiang Province (Mao et al., 2007). In another study, Liu et al. (2010) proposed the use of the apple florescence freezing injury insurance index developed on the basis of different levels of low temperature freezing damage as measured using this effect in Shaanxi apples, while Yang et al. (2013) proposed the winter wheat planting weather index. This latter measure was designed in Anhui Province with reference to the five main kinds of meteorological disasters that influence agricultural wheat growth and has been successfully applied within the city of Suzhou (Yang et al., 2013). Designing weather index-based insurance products is difficult if they are expected to encompass a large area; indeed, few such products are currently available for use at the provincial level. The products that are available have mostly been based on research areas selected at municipal or county levels; a few studies have even utilized villages and towns as their research areas (Lou et al., 2011).

Summer maize is the third most important grain crop grown in Anhui Province, as well as a key feed and industrial raw material (Sheng et al., 2014). The main agricultural areas for this crop are concentrated in the arid Huaibei region within the Huaihe Basin, a zone that experiences marked precipitation variability throughout the growing season. The tassel appearance maturity stage of summer maize is the most critical period for a water shortage, as during this phase, precipitation only encompasses $64 \%$ of water demand. This phase is also a critical production time as other precipitation periods can generally meet the water demand requirements of maize (Yang et al., 2016). An analysis of precipitation anomalies and the drought yield reduction rate of summer maize in Anhui Province is therefore presented in this study, alongside a drought insurance claim compensation standard for this crop. A revision of the drought weather index is also presented in this study that takes into account relative humidity during the initial phase of the insurance period. Finally, an insurance product based on the drought weather index for summer maize is proposed.

\section{Materials and Methods}

\subsection{Materials}

The meteorological data utilized in this study consists of precipitation, temperature, and hours of sunshine records collected at 15 stations within the Anhui Province summer maize planting area between 1971 and 2015 (Fig. 1). Geographic data was also collected for analysis in this study, including the latitude, longitude, and elevation of each county as well as summer maize yields and observational records collected across the growth period for nearly 40 years. These data were supplied by the Meteorological Information Center of Anhui Province". The output data of summer maize in Anhui Province come from Statistics Bureau of Anhui Province. 


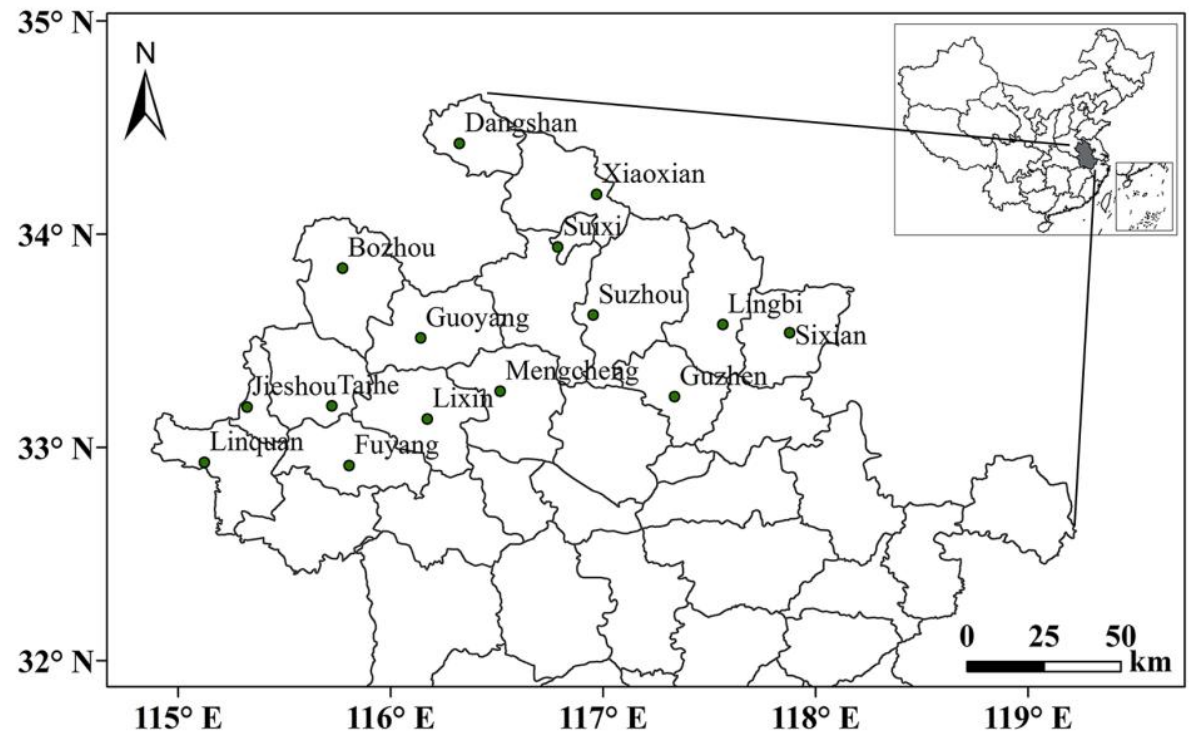

Fig. 1. Map to show the distribution of summer maize agro-meteorological observation stations throughout Anhui Province.

Observational data for the summer maize growth period, yield data treatments, and the weather index model were compared via conventional statistical analyses using the software packages SPSS and Excel.

\subsection{Summer Maize Drought Weather Index}

Applying the design principle (Yang et al., 2013) that underlies the Anhui Province winter wheat weather index, a drought index for summer maize should incorporate factors that are less influenced by human activities, should be simple to calculate, and easy to understand and popularize. Among the currently available domestic drought monitoring indices (Table 1), the precipitation anomaly percentage index does possess these characteristics and utilizes data that is easy to obtain. This measure has also been widely applied to assess meteorological and agricultural droughts and utilized in other research areas. This study therefore

Table 1. Comparison of the advantages and disadvantages of different drought indices.

\begin{tabular}{|c|c|c|c|}
\hline Drougl & index & Advantages & Disadvantages \\
\hline \multirow{3}{*}{$\begin{array}{l}\text { Drought index based } \\
\text { on precipitation }\end{array}$} & Rainfall index & Quick, simple, and practical & $\begin{array}{l}\text { Takes just a single precipitation factor } \\
\text { into account and does not consider the } \\
\text { effects of crops, the underlying surface, } \\
\text { and other related factors }\end{array}$ \\
\hline & $\begin{array}{l}\text { Percentage } \\
\text { precipitation } \\
\text { anomaly }\left(\mathrm{P}_{\mathrm{a}}\right)\end{array}$ & Clear meaning and simple method & $\begin{array}{c}\text { Does not consider the effects of soil } \\
\text { moisture and relies heavily on the } \\
\text { average values }\end{array}$ \\
\hline & $\begin{array}{l}\text { Standardized } \\
\text { precipitation } \\
\text { index }\end{array}$ & $\begin{array}{c}\text { Calculation is stable and } \\
\text { spatiotemporal distribution } \\
\text { differences in precipitation are } \\
\text { eliminated }\end{array}$ & $\begin{array}{c}\text { Calculation is tedious, difficult to utilize } \\
\text { and promote }\end{array}$ \\
\hline \multirow{2}{*}{$\begin{array}{l}\text { Drought index based } \\
\text { on soil moisture }\end{array}$} & $\begin{array}{l}\text { Soil relative } \\
\text { humidity }\end{array}$ & Intuitive, data is easy to access & $\begin{array}{l}\text { Determination difficulty and index is } \\
\text { poorly representative }\end{array}$ \\
\hline & Palmer drought index & $\begin{array}{l}\text { Crop water supply can respond } \\
\text { sensitively }\end{array}$ & $\begin{array}{c}\text { Calculation is tedious, difficult to utilize } \\
\text { and promote }\end{array}$ \\
\hline Crop drought index & $\begin{array}{l}\text { Leaf water potential, } \\
\text { stomatal } \\
\text { conductance, and cell } \\
\text { sap concentration }\end{array}$ & $\begin{array}{l}\text { Can directly and sensitively reflect } \\
\text { crop water supply deficit }\end{array}$ & $\begin{array}{c}\text { A large number of field tests are required } \\
\text { to obtain the necessary parameters, data } \\
\text { representation is limited, and accuracy } \\
\text { needs to be improved }\end{array}$ \\
\hline Comprehensive index & $\begin{array}{l}\text { Crop water stress } \\
\text { index }\end{array}$ & $\begin{array}{l}\text { Reflects the combined effects of soil, } \\
\text { plant factors, and meteorological }\end{array}$ & $\begin{array}{c}\text { Calculation is tedious, difficult to utilize } \\
\text { and promote }\end{array}$ \\
\hline
\end{tabular}


builds on the Anhui Province drought weather index for summer maize and analyzes the relationship between negative precipitation anomalies at different growth stages and the crop yields of summer maize across this region using meteorological and agricultural meteorological station data from 15 cities province-wide.

The negative precipitation anomaly of summer maize during the tassel appearance maturity stage (i.e. between the middle of August and early September) was chosen $\mathrm{mm}$ and $40 \mathrm{~mm}$ of precipitation, while a $50 \mathrm{~mm}$ level can relieve a moderate drought, and more than this can relieve a severe drought (Table 2) (Ma et al., 2001).

As the initial state of the insurance period is not considered arid when constructing the summer maize drought weather index because soil relative humidity at the start of the study period (August $11^{\text {th }}$ ) is suitable (i.e. wet), we revised equation (1) on the basis of the data in Table 2. The modified expression used in this study is

Table 2. The level of precipitation required to relieve drought in the Huaibei region of Anhui Province (mm).

\begin{tabular}{cccc}
\hline Season & Mild drought $(65 \% \geq \mathrm{SW}>55 \%)$ & Moderate drought $(55 \% \geq \mathrm{SW}>45 \%)$ & Severe drought $(\mathrm{SW} \leq 45 \%)$ \\
\hline Summer & $30-40$ & 50 & $\geq 50$ \\
\hline
\end{tabular}

Abbreviation: SW, relative humidity of the top $20 \mathrm{~cm}$ soil layer

in this study as the summer maize drought weather index for Anhui Province. This negative precipitation anomaly has a negative percentage value.

Precipitation anomaly percentage was calculated as follows:

$$
P_{a}=\frac{P-\bar{P}}{\bar{P}} \times 100 \%
$$

In this expression, $P_{a}$ denotes the percentage of precipitation anomalies, while $P$ denotes precipitation over a given period, and $\bar{P}$ refers to annual average precipitation over the same period.

\subsection{Revising the Summer Maize Drought Weather Index for use in the Huaibei Region}

The Huaibei region of Anhui Province is characterized by the presence of sandy black soils which have poor water retention capabilities and are therefore sensitive to both droughts and waterlogging. The distribution of summer maize roots is also relatively shallow, mainly within the top $20 \mathrm{~cm}$ of the soil layer; thus, if the soil surface dries out, crops cannot grow normally. Thus, in the absence of supplementary water from precipitation or irrigation, soil moisture will gradually decrease (i.e. water is consumed) over time; the soil moisture loss rate varies significantly depending on weather, soil and crop type, and other factors.

In previous research, Ma et al. (2001) noted that mild droughts can be significantly alleviated, or relieved, in the summer (between July and August) by between 30 as follows:

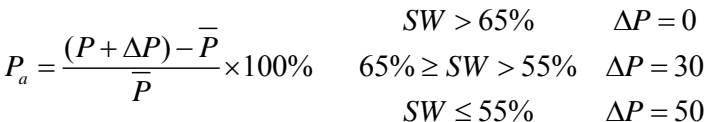

In this expression, $P_{a}$ denotes the precipitation anomaly percentage, $P$ refers to precipitation $(\mathrm{mm})$ over a given time period, $\Delta P$ denotes the precipitation $(\mathrm{mm})$ required to relieve a drought, $\bar{P}$ denotes average precipitation $(\mathrm{mm})$ over the 40 years of the study period, and $S W$ denotes the relative humidity (\%) of the top 20 $\mathrm{cm}$ soil layer on August $11^{\text {th }}$.

\section{Results}

\subsection{The Relationship Between Drought Weather Index and Summer Maize Yield Reduction}

There are many reasons for the decline in summer maize. Not all of them are affected by drought. Therefore, this study select the year of drought-induced reduction in summer maize as the data sample to calculate the relationship between summer drought index and yield reduction.

Selection of a typical year of drought: Calculate the cumulative wetting index of each station by ten - days periods from mid-June to mid-September (Ma et al. 2008). Cumulative wetting index by ten - days periods $\leqslant-0.40$ indicates the drought. If the rate of cut-off is selected, the year of dryness corresponding to the period 
of development will be eliminated only for a few days. If for some drought years, compare that with its historical facts, and if it is prone to drought, it is reserved for this ten days.

Building on data that describes the growth and development of summer maize in Anhui Province, precipitation records for this crop during the tassel appearance maturity stage were collected from 15 meteorological stations within the Huaibei region encompassing the period between 1971 and 2010. These data were then used to calculate values of the summer maize drought weather index. A trend equation was then deduced based on summer maize yields by applying a linear sliding average method to simulate this change (Xu et al., 2009). The correlation between summer maize drought weather index and yield was then expressed as a coefficient.

The expression used to calculate the drought weather index (i.e. negative precipitation) of summer maize
In this expression, $x$ denotes the yield reduction rate of summer maize, and $H$ denotes to the drought weather index of summer maize. The data collected for this study were used to verify this equation and resulted in $P$ values of 0.019 and 0.007 , both below the 0.05 significance level. Similarly, the coefficient of determination in the regression equation for summer maize drought index and yield reduction rate is 0.336 , also below the 0.05 significance level; this result demonstrates that the regression equation fits well to the data and can adequately reflect summer maize drought disasters in Anhui Province and their relationship with production. Thus, based on equation 4 , data that describes the relationship between drought weather index and summer maize yield rate is presented in Table 3.

The data presented in Table 3 show that when the drought weather index of summer maize was $50 \%$, the yield reduction rate of local maize was $26 \%$. Similarly,

Table 3. The relationship between drought weather index $(\mathrm{H})$ and yield reduction rate for summer maize.

\begin{tabular}{llllll}
\hline $\mathrm{H}(\%)$ & Yield reduction rate $(\%)$ & $H(\%)$ & Yield reduction rate $(\%)$ & $H(\%)$ & Yield reduction rate $(\%)$ \\
\hline 10 & 15 & 45 & 24 & 80 & 34 \\
15 & 16 & 50 & 26 & 85 & 35 \\
20 & 17 & 55 & 27 & 90 & 37 \\
25 & 19 & 60 & 29 & 95 & 38 \\
30 & 20 & 65 & 30 & 100 & 40 \\
35 & 22 & 70 & 31 & & \\
40 & 23 & 75 & 33 & & \\
\hline
\end{tabular}

during the tassel appearance maturity stage can be deduced from equation (1), as follows:

$$
H=-\frac{P_{c}-\overline{P_{c}}}{\bar{P}_{c}} \times 100 \%
$$

In this expression, $H$ denotes the drought index of summer maize during the tasseling milk stage, $P_{c}$ denotes actual precipitation (i.e. during the period between the middle of August and September $10^{\text {th }}$ ) throughout this stage, and $\bar{P}_{c}$ refers to the average precipitation seen during this stage over the last 40 years.

The resultant regression equation for the summer maize drought index and yield reduction rate within Anhui Province is therefore as follows:

$$
x=0.278 H+11.8
$$

when the drought weather index was $70 \%$, the yield reduction rate was $31 \%$, whereas when it was $100 \%$ (i.e. no precipitation throughout this period), the yield reduction rate of maize was $40 \%$.

The relationship between calculated drought weather index and yield reduction rate based on summer maize drought grade across Anhui Province was also calculated (Table 4). These data show that the grade remained consistent, which means that equation (4) can be used to adequately express the actual local situation.

\subsection{Developing a Compensation Standard Based on the Drought Weather Index of Summer Maize}

Records from local farmers show that the maize yield in the Huaibei region of Anhui Province can reach 7,500 $\mathrm{kg} / \mathrm{ha}$ if there are no meteorological disasters. Thus, as 
Table 4. Summer maize drought grade divisions in the Huaibei region of Anhui Province.

\begin{tabular}{lll}
\hline Drought grade & Yield reduction Rate $(\%)$ & Negative precipitation anomaly of summer maize during the tassel-milk stage (\%) \\
\hline Light drought & $<10$ & $<10$ \\
Moderate drought & $10-23$ & $10-40$ \\
Heavy drought & $23-31$ & $40-70$ \\
Severe drought & $>31$ & $>70$ \\
\hline
\end{tabular}

the current market price for maize is $2.2 \mathrm{RMB} / \mathrm{kg}$, the harvest output value can reach $16,500 \mathrm{RMB} / \mathrm{ha}$. The data presented in Table 3 also show that a drought during the growing season can lead to a $40 \%$ reduction in summer maize yield. This means that if the output value per hectare of harvest is $16,500 \mathrm{RMB} / \mathrm{ha}$, a drought can cause a maximum summer maize loss of $6,600 \mathrm{RMB} / \mathrm{ha}$. A guarantee level of $70 \%$ was therefore selected, taking the local situation into account; this translates to an insurance value of RMB 4,620 (i.e. $0.7 \times$ 6,600). The data presented in Fig. 2 show that the amount of compensation per hectare is equal to the amount of insurance per hectare multiplied by the compensation ratio.

The premium rate can be calculated from the insurance company's claim data for many years. The local weather index and crop yield reduction are important factors affecting the rate.

The data collected in this study reveal an average compensation probability of $10.8 \%$ at each site within the Huaibei area over the period between 1971 and 2010. This equates to an average compensation payout amount per year of 2,194.5 RMB/ha. Thus, as the insurance rate for the drought index of summer maize in the Huaibei region is equal to the compensation probability multiplied by the average payout amount over a compensation year, $10.8 \% \times 2,194.5$ equates to 237 $\mathrm{RMB} / \mathrm{ha}$

Data therefore show that the insurance rate for summer maize droughts in the Huaibei region should be $237 \mathrm{RMB} / \mathrm{ha}$.

The equation used to calculate an insurance premium is as follows:

$$
\begin{array}{r}
\text { Insurance premium }=\text { insurance rate } \times \text { insurance } \\
\text { quantity (ha) (5). }
\end{array}
$$

Thus, the insurance amount for summer maize in this region is $\mathrm{RMB} 4,620 / \mathrm{ha}$; compensation standards for situations when the summer maize drought index is greater than $40 \%$ are shown in Fig. 2 .

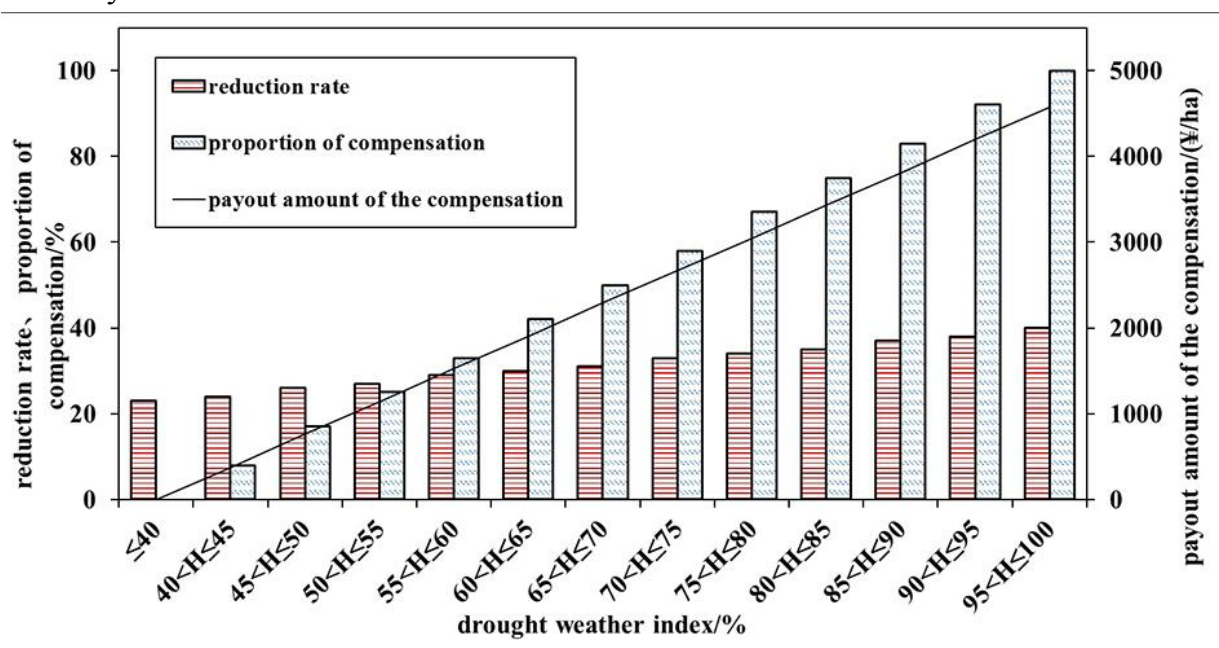

Fig. 2. Payment standards based on summer maize drought weather index insurance. 


\subsection{Revision of the Drought Weather Index of Summer Maize}

As discussed above, because soil relative humidity is arid at the start of the insurance period (August $11^{\text {th }}$ ), a premium rate based on the summer maize drought weather index was revised on the basis of equation (3), as follows:

$$
H=-\frac{\left(P_{c}+\Delta P\right)-\overline{P_{c}}}{\bar{P}_{c}} \times 100 \% \quad \begin{array}{cc}
S W>65 \% & \Delta P=0 \\
65 \% \geq S W>55 \% & \Delta P=30 \\
S W \leq 55 \% & \Delta P=50
\end{array}
$$

In this expression, $H$ refers to the dry weather index of summer maize during the tasseling milk stage (i.e. between the middle of August and early September), while $P_{c}$ denotes actual precipitation $(\mathrm{mm})$ during this stage, $\Delta P$ denotes the precipitation $(\mathrm{mm})$ required to relieve drought $(\mathrm{mm})$, and $S W$ refers to the relative humidity (\%) of the top $20 \mathrm{~cm}$ of soil on August $11^{\text {th }}$.

\subsection{Testing the Drought Weather Index of Summer Maize}

The drought weather index of summer maize is expressed as a percentage of negative precipitation anomalies. Thus, both the role of soil moisture and data that could be used for modeling the correspondence with initial soil moisture non-arid status are not usually taken into account as components of this index. According to the -Cha Meteorological Disaster Ceremony (Anhui Volume)", the period between August and early September 1985 in this province was hot and experienced just a small amount of precipitation because of the presence of a strong and stable subtropical higher. In addition to these conditions in the northern Huaibei region, other areas of Anhui Province were also hot at this time and experienced little rain; this year was also characterized by a significant autumn drought controlled by the subtropical high. Indeed, throughout the period between August and early September 1986, all regions of this province experienced continuously high temperature, little rain, and both summer and autumn droughts; for these reasons, the drought weather index of summer maize was calculated using precipitation data for the period between August 11 $1^{\text {th }}, 1985$, and September 10th, 1986.
Comparing the drought indices calculated before, and after, this revision (Table 5) shows that most of the sites in Huaibei in 1985 and all sites during 1986 experienced droughts. This revised drought weather index is therefore more realistic than those previously employed.

Table 5. Standard payments for summer maize drought weather index insurance

\begin{tabular}{lllll}
\hline Site & $\begin{array}{l}1985 \\
\text { (before } \\
\text { revision) }\end{array}$ & $\begin{array}{l}\text { (after } \\
\text { revision) }\end{array}$ & $\begin{array}{l}\text { 1986 } \\
\text { (before } \\
\text { revision) }\end{array}$ & $\begin{array}{l}\text { (after } \\
\text { revision) }\end{array}$ \\
\hline Dangshan & -111.41 & -65.25 & -24.26 & 21.90 \\
Xiaoxian & -40.46 & 8.65 & 1.97 & 51.08 \\
Bozhou & -66.65 & -18.20 & -24.02 & 24.43 \\
Linquan & 57.57 & 102.61 & 8.39 & 53.43 \\
Jieshou & 57.84 & 102.13 & -23.12 & 21.17 \\
Taihe & -31.52 & 17.48 & -12.70 & 36.30 \\
Suixi & -216.45 & -165.01 & -41.25 & 10.19 \\
Guoyang & -145.96 & -97.49 & -44.07 & 4.41 \\
Lixin & 46.27 & 98.74 & -27.92 & 24.55 \\
Mengcheng & 8.26 & 63.39 & -29.24 & 25.90 \\
Suzhou & -157.10 & -107.83 & -38.85 & 10.42 \\
Lingbi & 32.32 & 77.44 & -30.76 & 14.36 \\
Sixian & 31.77 & 79.02 & 21.65 & 68.91 \\
Guzhen & 41.61 & 92.21 & 0.32 & 50.92 \\
\hline
\end{tabular}

\subsection{Application}

In August 2015, the Anhui Meteorological Bureau commissioned the Guoyuan Agricultural Insurance Company" to carry out a pilot study on the maize drought index within the city of Huaibei in Suixi County, Anhui Province, China. The Bureau therefore signed a maize drought index insurance contract with six wealthy and influential families who cultivate around 188 hectares of summer maize with an insurance value of 869,176 RMB. Compensation was set to start for these farmers when the drought index was greater than $40 \%$ over the set time period defined above (between August $11^{\text {th }}$ and September $10^{\text {th }}$ ). Continuous precipitation was recorded within the Huaibei region throughout August 2015, and meteorological observation data from Suixi County station revealed a drought index of $38.7 \%$ over this time period. As this index value did not meet the predefined insurance payment conditions, claims were not produced. Indeed, subsequent to this insurance pilot experiment, investigations showed that maize plots remained in 
good condition and no drought disaster was recorded; this experiment confirmed that maize drought index insurance can realistically describe actual risk.

\section{Discussion and Conclusion}

\subsection{Discussion}

A summer maize drought weather index is proposed in this study and practical applications were used to derive a compensation rate for each county within Anhui Province on the basis of objective meteorological data, independent of actual crop yields. In addition to the advantages of easy handling and simple claims, this index is also conducive to promoting the use of more risky areas to farmers in order to enhance crop management and adjust planting structures. Thus, compared with traditional agricultural (Makki et al., 2001) and regional production index-based insurance (Ozaki et al., 2009), the summer maize drought weather index proposed in this study is based on a model of the actual relationship between meteorological factors and crop yield reduction rates. This means that meteorological data provided by a third party independent of the insurance companies and farmers is used as the basis for both protection and subsequent compensation payments. This approach therefore effectively avoids disputes that might occur between parties during the processes of insurance and payment. Building on the previous work of Mao et al. (2007), the drought index of summer maize is also revised in this study, utilizing the status of soil moisture during the initial insurance period. The critical summer maize production period (i.e. the tassel appearance maturity stage) was selected for application in this study; as this time period is even shorter in our study, calculated insurance rates are even more accurate.

However, whether or not a drought weather indexbased insurance product is practical depends on a number of factors, including the distance between a reference station and adjacent crop site; it is important to ensure that climatic conditions at a planting site and associated reference weather station are comparable. In addition, as yield loss is not entirely related to weather index (Skees, 2008; Turvey et al., 2010), undesirable effects could also occur; crop losses without compensation, and payments without losses. Finally, the demand for weather-based insurance products is generally low amongst target customers, mainly because low income farmers who are most likely to benefit from these schemes tend to be suspicious of their credibility (Binswanger-Mkhize, 2012). Nevertheless, the drought risk insurance product outlined in this study was piloted within the city of Huaibei in Suixi County, Anhui Province, over the course of August 2015; the results of this initial test showed that a drought index-based insurance product does accurately reflect actual risk.

A number of issues should be addressed in future research, including the fact that this study did not take into account the influence of heavy rainfall or long-term droughts on summer maize yields before the critical period of summer growth. Continuous improvements are therefore required to develop the drought weather index model proposed in this study. Indeed, the data used in the design of this index, and whether or not environmental differences between collection sites and insured land will lead to compensation errors should also be addressed in future research.

\subsection{Conclusion}

Building on the previous domestic and international research results, this study addressed the growth of summer maize in Anhui Province, China, in order to elucidate the relationship between yield reduction rate and drought index. A drought index model for summer maize claims within the province was therefore constructed, a series of disaster insurance rates were determined, and an insurance product was designed based on a statistical analysis of meteorological, crop yield, and growth period data.

A regression approach was used to evaluate the relationship between the summer maize drought weather index proposed in this study and yield reductions in Anhui Province. A significance test was then applied to show that the resultant regression equation model fitted well with available data and can be used to accurately predict the drought grade of summer maize in Anhui Province, indicative of the actual local situation.

A series of insurance coverage standards are proposed based on the summer maize drought weather index, and a Huaibei region summer maize premium rate of $237 \mathrm{RMB} / \mathrm{ha}$ is suggested. The results of this study also show that the volume of insurance units up to a level of 4,620 RMB/ha can be maintained when a higher than $40 \%$ summer drought index is seen. Relevant insurance probabilities are also revised in this 
study, based on the soil relative humidity during the initial insurance period of drought.

The results of a pilot study on summer maize drought index insurance carried out in August 2008 within the city of Huaibei in Suixi County, Anhui Province, confirm that this product does accurately reflect actual risk.

\section{Acknowledgements}

This research was supported by the National Natural Science Foundation of China (Grant No. 41571018).

\section{References}

1. Antón, J., Cattaneo, A., \& Kimura, S. et al. (2013). Agricultural risk management policies under climate uncertainty. Global Environmental Change, 23(6): 17261736. doi.org/10.1016/j.gloenvcha.2013.08.007.

2. Binswanger-Mkhize, H. P. (2012). Is there too much hype about index-based agricultural insurance? Journal of Development Studies, 48(2): 187-200. doi: 10.1080/00220388.2011.625411.

3. Blanc, E. (2012). The impact of climate change on crop yields in Sub-Saharan Africa. American Journal of Climate Change, 1(1): 1-13. doi: 10.4236/ajcc.2012.11001.

4. Bobojonov, I., Awhassan, A., \& Sommer R. (2014). Index-based insurance for climate risk management and rural development in Syria. Climate and Development, 6(2): 166-178. doi.org/10.1080/17565529.2013.844676.

5. Cao, J., Li, S., \& Li, Y. (2013). Design of products for winter wheat agro-meteorological index insurance in Jiangsu Province. International Journal of Hybrid Information Technology, 6(5): 37-48. doi: 10.14257/ijhit.2013.6.5.04.

6. Chen, W., Hohl, R., \& Tiong, L. K. (2017). Rainfall index insurance for corn farmers in Shandong based on highresolution weather and yield data. Agricultural Finance Review, 77(2) 35-41. doi.org/10.1108/AFR-10-20150042.

7. Coble, K. H., Hanson, T., \& Miller, J. C. et al. (2003). Agricultural insurance as an environmental policy tool. Journal of Agricultural \& Applied Economics, 35(2): 391-405. doi: 10.1017/S1074070800021350.

8. Finger, R., Pelka, N., \& Musshoff, O. (2014). Hedging effectiveness of weather index-based insurance in China. China Agricultural Economic Review, 6(2): 212-228. doi: 10.1108/CAER-11-2012-0124.

9. Jin, J., Wang, W., \& Wang, X. (2016). Farmers' risk preferences and agricultural weather index insurance uptake in rural China. International Journal of Disaster Risk Science, (4): 1-8. doi: 10.1007/s13753-016-0108-3.
10. Turvey, C. G., \& Kong, R. (2010). Weather risk and the viability of weather insurance in China's Gansu, Shaanxi, and Henan provinces. China Agricultural Economic review, 2(1): 5-24.

11. Leblois, A., \& Quirion, P. (2013). Agricultural insurances based on meteorological indices: realizations, methods and research challenges. Meteorological Applications, 20(1): 1-9.

12. Liu, Y. N., He, W. L., \& Li, Y. L. et al. (2010). A study on the risk index design of agricultural insurance on apple florescence freezing injury in the Shaanxi fruit zone. Chinese Journal of Agrometeorology, 31(1): 125-124. (in Chinese) doi:10.3969/jissn.1000-6362.

13. Lou, W. P., Ji, Z. W., \& Qiu, X. F. et al. (2011). Design of weather index insurance contact for tea frost. Journal of Natural Resources, 26(12): 2050-2060. (in Chinese) doi: 10.11849/zrzyxb.2011.12.005

14. Lu, Y., Ramirez, O. A., Rejesus, R. M., \& Knight, T. O. et al. (2008). Empirically evaluating the flexibility of the Johnson family of distributions: A crop insurance application. Agricultural \& Resource Economics Review, 37(1): 79-91. doi: 10.1017/S1068280500002161.

15. Makki, S. S., \& Somwaru, A. (2001). Evidence of adverse selection in crop insurance markets. Journal of Risk and Insurance, 68(4):685-708. doi: 10.2307/2691544.

16. Ma, X. Q., Sheng, S. X., \& Zhang, A. M. (2001). Influence of precipitation on drought developing in north of the Yangtze River in Anhui. Agricultural Meteorology, 22(3): 15-19. (in Chinese)

17. Ma, X. Q., Wu, W. Y., \& Zhang, H. (2008). Analyzing spatial and temporal variations of agricultural drought and waterlog in Jianghuai area through accumulated humidity index. Resources Science, 2008, 30(3): 371-377. (in Chinese)

18. Mao, Y. D., Wu, L. H., \& Miao, C. M. et al. (2007). A reference design for citrus freeze damage insurance by using meteorological index in Zhejiang Province. Chinese Journal of Agrometeorology, 28(2): 226-230. (in Chinese)

19. Mornet, A., Opitz, T., \& Luzi, M. et al. (2015). Index for predicting insurance claims from wind storms with an application in France. Risk Analysis, 35(11): 2029-2056. doi: 10.1111/risa.12395.

20. Ozaki, V. A., \& Silva, R. S. (2009). Bayesian ratemaking procedure of crop insurance contracts with skewed distribution. Journal of Applied Statistics, 36(4): 443-452. doi: $10.1080 / 02664760802474256$.

21. Panda, A., Sharma, U., \& Ninan, K. N. et al. (2013). Adaptive capacity contributing to improved agricultural productivity at the household level: empirical findings highlighting the importance of crop insurance. Global Environmental Change, 23(4): 782-790. doi: 10.1016/j.gloenvcha.2013.03.002. 
22. Sheng, S. X., Zhang, J. J., \& Wang, X. D. (2014). Spatialtemporal distribution of climatic suitability of summer maize in Anhui Province. Geographical Research, 35(1): 1467-1476. (in Chinese) doi: 10.11821/dlyj201408007.

23. Skees, J. R., 2008. Challenges for use of index-based weather insurance in lower income countries. Agricultural Finance Review, 68(1): 197-217. doi: 10.1108/00214660880001226.

24. Thomas, D. S. G., Twyman, C., \& Osbahr, H. et al. (2007). Adaptation to climate change and variability: farmer responses to intra-seasonal precipitation trends in South Africa. Climatic Change, 83(3): 301-322. doi: 10.1007/s10584-006-9205-4.

25. Xu, Y., Ma, X.Q., \& Yue, W. (2009). Study on quantitative assessment of water logging disaster losses of single-season rice in Anhui Province. Journal of Anhui Agricultural Sciences, 37(2): 722-726. (in Chinese) doi: 10.13989/j.cnki.0517-6611.

26. Yang, T. M., Liu $\square$ B. C., \& Sun, X. B. et al. (2013). Design and application of the weather indices of winter wheat planting insurance in Anhui Province. Chinese Journal of Agrometeorology, 34(2): 229-235. (in Chinese) doi: 10.3969 /j.issn.1000-6362.

27. Yang, T. M., Xu, Y., \& Sun $\square$ X. B. et al. (2016). Design and application of the drought weather index insurance of summer maize in Anhui Province. Meteorological Monthly, 42(4): 450-455. (in Chinese)

28. Zhang, J., Zhang, Z., \& Tao, F. (2017). Performance of temperature-related weather index for agricultural insurance of three main crops in China. International Journal of Disaster Risk Science, 8(1): 78-90. doi: 10.1007/s13753-017-0115-z.

29. Zhang, Z. (2014). Spatial pattern and decadal change of agro-meteorological disasters in the main wheat production area of China during 1991-2009. Journal of Geographical Sciences, 24(3): 387-396. doi: 10.1007/s11442-014-1095-1. 